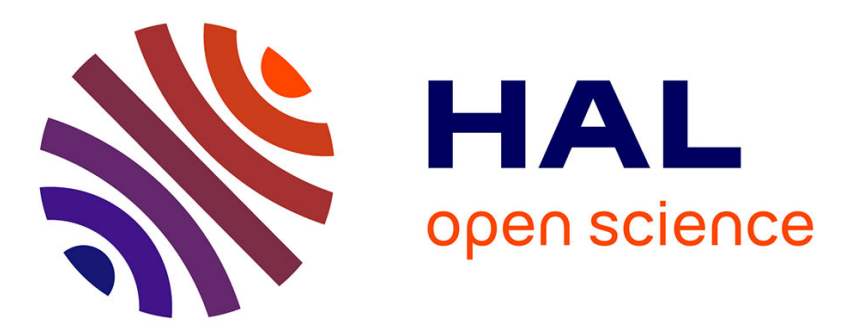

\title{
Temperature field in a rotating roller subjected to interface heating
}

T. Osman, S. Guenoun, A. Boucheffa

\section{To cite this version:}

T. Osman, S. Guenoun, A. Boucheffa. Temperature field in a rotating roller subjected to interface heating. European Physical Journal: Applied Physics, 2010, 50 (2), pp.20504. 10.1051/epjap/2010042 . hal-00589715

\section{HAL Id: hal-00589715 https://hal.science/hal-00589715}

Submitted on 1 May 2011

HAL is a multi-disciplinary open access archive for the deposit and dissemination of scientific research documents, whether they are published or not. The documents may come from teaching and research institutions in France or abroad, or from public or private research centers.
L'archive ouverte pluridisciplinaire HAL, est destinée au dépôt et à la diffusion de documents scientifiques de niveau recherche, publiés ou non, émanant des établissements d'enseignement et de recherche français ou étrangers, des laboratoires publics ou privés. 


\title{
Temperature field in a rotating roller subjected to interface heating
}

\author{
T. Osman*, S. Guenoun, A. Boucheffa \\ Université Paris Sud, IUT d'Orsay, Département MP \\ Plateau du Moulon 91400 Orsay, France.
}

*Corresponding author: talaat.osman@u-psud.fr

Phone: +33 (0) 169336079

\begin{abstract}
:
The thermal behaviour of a rotating roller, subjected to surface heat sources is studied in this paper using an analytical solution, developed for this purpose. The roller is composed of a solid cylinder, rotating with a constant angular velocity, and is heated at its peripheral surface by two different heat sources. The analytical solution is entirely explicit and does not necessitate any hypothesis neither on the speed nor on the physical or geometrical parameters of the roller. The characteristic parameters are presented in dimensionless forms and are used to analyse the temperature distribution as function of their variations. Thermal maps are also presented using the proposed solution. They show that the thermal gradients are localized at the vicinity of the friction zone, and that the thermal gradients zones decrease when the angular speed increases.
\end{abstract}

PACS numbers:

44.05.+e Analytical and numerical techniques

44.10. $+\mathrm{i}$ Heat conduction

68.35.Ct Interface structure and roughness 


\section{Introduction}

Rotating rollers, subjected to localized surface heating, exist in many industrial processes such as rolling mills, bearings, train wheels, etc. Important amount of heat is generated in a narrow zone situated at the vicinity of such localized sources. This heating causes mechanical stresses and leads to material damages such as wear and cracks phenomena.

Recent numerical models, presented to deal with rolling processes [1,2] have shown that the thermal gradients can attain important levels which depend on the heat dissipated by friction, the rolling speed and the heat convection coefficient.

Many other works [3-8] dealt with the evaluation of temperature in solids subjected to frictional heating. The difficulty of calculations resides in the solid mobility with respect to the contact area. This mobility is characterised by the dimensionless Peclet number: $P e=V \ell / \alpha$, where $V$ is the relative velocity, $\ell$ the characteristic length and $\alpha$ the thermal diffusivity of the material. The precision of numerical models depends on the mesh size, which vary with the Peclet number. In fact, the number of nodes should be high for high Peclet number. This is why an analytical solution - if it exists - is more interesting.

The temperature distribution due to friction process necessitates a good knowledge of the contact parameters. In fact, the interface is always imperfect - due to the roughness - from a mechanical and thermal point of view. Recent theoretical and experimental works [9-12] have been developed to characterise the thermal parameters which govern the heat transfer at the vicinity of a sliding interface.

In certain industrial applications, the solids are provided with surface coating. A recent study has been carried out to analyse the effect of surface coating on the thermal behaviour of a solid subjected to friction process [13].

A two-dimensional steady state analytical solution is presented here to deal with the problem of a rotating cylinder, subjected to localized heating on different parts of its periphery. This solution is explicit, easy to program and does not necessitate any iterative process. No restrictive conditions are imposed on the speed.

In what follows, we describe the problem and give the details of the proposed solution. Then, the temperature distributions with the variation of physical dimensionless parameters are studied. Finally, thermal maps are presented to illustrate the thermal phenomenon, which is related to the rotation speed.

\section{Description of the problem}

We consider a rotating cylinder, subjected to two diametrically opposed heat sources (Figure 1). This situation is similar to a roller bearing in contact with the two rings. It can also represent a rolling mill, if only one heat source is considered. The case of multiple heat sources, placed any where on the cylinder periphery can be easily treated using the proposed model. The cylinder, of radius $R$, rotates with a constant angular velocity $\omega$ and receives heat trough two different angular apertures: $2 \xi_{0}$ (for a heat source of flux density $q_{0}$ ) and $2 \xi_{1}$ (for a heat source of flux density $q_{1}$ ). The cylinder surface is cooled by convection of coefficient $h$ and zero ambient temperature.

A steady state heat transfer with constant thermal properties is considered. An analytical, explicit and exact solution is seeked to compute the two-dimensional temperature fields $T(r, \varphi)$. 


\section{Analytical model}

\subsection{Governing equations}

The heat diffusion in the roller is governed by the heat equation in polar coordinates, which can be written (with respect to the heat sources) as follows:

$$
\frac{\partial^{2} T}{\partial r^{2}}+\frac{1}{r} \frac{\partial T}{\partial r}+\frac{1}{r^{2}} \frac{\partial^{2} T}{\partial \varphi^{2}}-\frac{\omega}{\alpha} \frac{\partial T}{\partial \varphi}=0
$$

Where $\alpha$ is the thermal diffusivity of the material. The term $\frac{\omega}{\alpha} \frac{\partial T}{\partial \varphi}$ represents the effect of roller relative motion with respect to the heat sources. This is the transport (or the convection) term.

The angular periodicity leads to the following equations:

$T(r,-\pi)=T(r, \pi)$

$\frac{\partial T(r,-\pi)}{\partial \varphi}=\frac{\partial T(r, \pi)}{\partial \varphi}$

The cylinder center temperature should be finite, i.e.:

$T(0, \varphi)$ is finite

The cylinder surface is subjected to the following boundary conditions:

$$
\lambda \frac{\partial T(R, \varphi)}{\partial r}=\left\{\begin{array}{lr}
q_{1} & |\varphi+\pi / 2| \leq \xi_{1} \\
q_{0} & |\varphi-\pi / 2| \leq \xi_{0} \\
-h T(R, \varphi) & \text { elsewhere }
\end{array}\right.
$$

Where $\lambda$ is the thermal conductivity.

The following dimensionless variables will be used in the solution:

$$
\begin{aligned}
& \rho=\frac{r}{R}, B i=\frac{h R}{\lambda}, P e=\frac{\omega R^{2}}{\alpha}, \theta=\frac{T}{\Delta T_{r}}, \Delta T_{r}=\frac{q_{a v} R}{\lambda}, \\
& q_{a v}=\frac{q_{0} \xi_{0}+q_{1} \xi_{1}}{\pi}, q_{0}^{*}=\frac{q_{0}}{q_{a v}}, q_{1}^{*}=\frac{q_{1}}{q_{a v}}
\end{aligned}
$$

Where $P e$ and $B i$ are the Peclet and Biot numbers respectively, and $\Delta T_{r}$ the reference temperature.

So, equations (1) to (5) can be written in the following dimensionless form: 
$\frac{\partial^{2} \theta}{\partial \rho^{2}}+\frac{1}{\rho} \frac{\partial \theta}{\partial \rho}+\frac{1}{\rho^{2}} \frac{\partial^{2} \theta}{\partial \varphi^{2}}-P e \frac{\partial \theta}{\partial \varphi}=0$

$\theta(\rho,-\pi)=\theta(\rho, \pi)$

$\frac{\partial \theta(\rho,-\pi)}{\partial \varphi}=\frac{\partial \theta(\rho, \pi)}{\partial \varphi}$

$\theta(0, \varphi)$ is finite

$\frac{\partial \theta(1, \varphi)}{\partial \rho}=\left\{\begin{array}{lr}q_{1}^{*} & |\varphi+\pi / 2| \leq \xi_{1} \\ q_{0}^{*} & |\varphi-\pi / 2| \leq \xi_{0} \\ -B i \theta(1, \varphi) & \text { elsewhere }\end{array}\right.$

\subsection{Analytical solution}

Equations (7) to (11) can be solved using the following Fourier frequency integral transform:

$\tilde{\theta}=\frac{1}{2 \pi} \int_{-\pi}^{\pi} \theta e^{-j n \varphi} d \varphi$

Taking the periodicity conditions (8) and (9) into consideration, equation (7) becomes a simple second order differential equation:

$\frac{d^{2} \tilde{\theta}}{d \rho^{2}}+\frac{1}{\rho} \frac{d \tilde{\theta}}{d \rho}-\left[\frac{n^{2}}{\rho^{2}}+j n P e\right] \tilde{\theta}=0$

The transformed boundary conditions become:

$\tilde{\theta}(0)$ is finite

$\frac{d \tilde{\theta}(1)}{d \rho}=\tilde{q}_{1}^{*}+\tilde{q}_{0}^{*}-B i \tilde{\theta}(1)$

with:

$\tilde{q}_{1}^{*}=q_{1}^{*} \frac{e^{j n \pi / 2} \sin \left(n \xi_{1}\right)}{n \pi} ; \tilde{q}_{0}^{*}=q_{0}^{*} \frac{e^{-j n \pi / 2} \sin \left(n \xi_{0}\right)}{n \pi}$

In Eq. (15) the terms $\frac{h}{2 \pi} \int_{-\pi / 2-\xi_{1}}^{-\pi / 2+\xi_{1}} \theta(1, \varphi) e^{-j n \varphi} d \varphi$ and $\frac{h}{2 \pi} \int_{\pi / 2-\xi_{0}}^{\pi / 2+\xi_{0}} \theta(1, \varphi) e^{-j n \varphi} d \varphi$ have been neglected for two reasons: (i) the size of the heated area is small compared to that of the roller 
and (ii) the heat convection coefficient is not very high $\left(h<200 \mathrm{~W} \cdot \mathrm{m}^{-2} \cdot K^{-1}\right.$, typically). Gecim and Winer [14] have shown that this assumption is valid when: $h \sqrt{\frac{2 \alpha}{\lambda \omega}} \leq 1$. This condition is well verified in tribological applications.

Two cases are distinguished to establish the solution:

(i) case: $n=0$

$\tilde{\theta}_{n=0}(\rho)=\frac{1}{B i}$

(ii) case: $n \neq 0$

$\tilde{\theta}_{n}(\rho)=\frac{\left(\tilde{q}_{1}^{*}+\tilde{q}_{0}^{*}\right) J_{n}\left(\gamma_{n, j} \rho\right)}{\gamma_{n, j} J_{n}^{\prime}\left(\gamma_{n, j}\right)+B i J_{n}\left(\gamma_{n, j}\right)}$

with:

$\gamma_{n, j}=\gamma_{n} e^{-j \pi / 4}, \gamma_{n}=\sqrt{n P e}, \gamma_{n, j} J_{n}^{\prime}\left(\gamma_{n, j}\right)=n J_{n}\left(\gamma_{n, j}\right)-\gamma_{n, j} J_{n+1}\left(\gamma_{n, j}\right)$

The terms $J_{n}$ and $J_{n+1}$ represent the Bessel function of the first kind, of order $n$ and $n+1$ respectively and $J_{n}^{\prime}$ is the derived Bessel function.

The inverse integral transform of equation (12) is given by the following expression:

$\theta(\rho, \varphi)=\sum_{n=0}^{\infty} \varepsilon_{n} \Re_{e}\left[\tilde{\theta}(\rho) e^{j n \varphi}\right], \varepsilon_{0}=1, \varepsilon_{n}=2(n=1,2, \ldots \infty)$

where $\mathfrak{R}_{e}$ indicates the real part of $\left[\tilde{\theta}(\rho) e^{j n \varphi}\right]$.

The substitution of $\tilde{\theta}(\rho)$ given by equations (17) - for $n=0$ - and (18) - for $n \neq 0$ - in equation (19) yields the final solution.

$\theta(\rho, \varphi)=\frac{1}{B i}+2 \sum_{n=1}^{\infty} \mathfrak{R}_{e}\left\{\frac{\left(\tilde{q}_{1}^{*}+\tilde{q}_{0}^{*}\right) J_{n}\left(\gamma_{n, j} \rho\right) e^{j n \varphi}}{n J_{n}\left(\gamma_{n, j}\right)-\gamma_{n, j} J_{n+1}\left(\gamma_{n, j}\right)+B i J_{n}\left(\gamma_{n, j}\right)}\right\}$

The Bessel functions, for which the argument is a complex number, can be expressed by the following relations: 


$$
\begin{aligned}
& J_{n}\left(\gamma_{n, j}\right)=J_{n}\left(\gamma_{n} e^{-j \pi / 4}\right)=e^{-j n \pi}\left[\operatorname{Ber}_{n}\left(\gamma_{n}\right)+j \operatorname{Bei}_{n}\left(\gamma_{n}\right)\right]=(-1)^{n}\left[\operatorname{Ber}_{n}\left(\gamma_{n}\right)+j \operatorname{Bei}_{n}\left(\gamma_{n}\right)\right] \\
& J_{n+1}\left(\gamma_{n, j}\right)=-(-1)^{n}\left[\operatorname{Ber}_{n+1}\left(\gamma_{n}\right)+j \operatorname{Bei}_{n+1}\left(\gamma_{n}\right)\right] \\
& J_{n}\left(\gamma_{n, j} \rho\right)=(-1)^{n}\left[\operatorname{Ber}_{n}\left(\gamma_{n} \rho\right)+j \operatorname{Bei}_{n}\left(\gamma_{n} \rho\right)\right]
\end{aligned}
$$

Where $\mathrm{Ber}_{n}$ and $B e i_{n}$ are the Kelvin functions of order $n$.

\section{Results and discussions}

The analytical solution given by equation (20) is used to calculate the roller temperature for different configurations (single or double contact) and different contact zone dimensions $\left(\xi_{0}\right.$, $\xi_{1}$ ) in addition to different dimensionless variables: Peclet number $P e$, Biot number $B i$, and $q^{*}$.

\subsection{Single contact configuration}

The analytical solution given by equation (20) can be applied to a single contact case. This can be done by considering one of the two heat fluxes equal to zero. In the present study, the value of $q_{1}$ is taken to be zero. The variation of the dimensionless surface temperature $\theta(\rho=1, \varphi)$ for a Biot number $B i=1$ and different Peclet number values $P e=5,10$ and 100 is shown on Figure 2. A strong temperature variation in the contact zone is observed at the lower Peclet number. The case of $P e=5$ corresponds to a nearly static roller, resulting in an almost symmetrical temperature distribution with respect to the heat source center. These results are coherent with those obtained in reference [1].

\subsection{Double contact configuration}

Figure 3 show the roller thermal maps for different Peclet numbers. The variation of this number has been obtained by changing the rotation velocity while maintaining the same material with the same dimensions. The numerical data are given in the caption of this figure. It can be seen that the thermal gradients are localized in a relatively narrow zone, situated near the contact areas. This zone decreases with the increase of rotation speed. It can be also seen that the temperature of certain internal zones are higher than that of the surface. In fact, since the roller is solid - non hollowed - and laterally insulated, it can evacuate the heat only through its external surface, outside the heated zone. This phenomenon is expressed by a periodic thermal solicitation leading to temperature gradient inversions and, hence, to residual stresses. A temperature homogeneity is also observed in a relatively wide domain, situated at the roller center.

Figure 4 shows the temperature angular dependence at different roller radius for identical contacts (same dimensions and same flux). A temperature increase is found at each passage in each contact zone. The surface temperature in the contact zone $(\rho=1)$ is naturally higher than that at the depth but, near $\rho=0.9$ the temperature becomes practically independent of the angular position. Finally, one can observe that the temperature inside the roller becomes higher than that of the surface in zones situated outside the contact zones. 


\section{Conclusions}

An analytical solution to calculate the temperature in a solid rotating roller, subjected to two peripheral heat sources is presented in this paper. This solution is easy to program and allows to obtain accurate results with very low computation time. It can be extended to other configurations (e.g. $\mathrm{N}$ contacts) without any difficulty. The obtained results show strong thermal gradients in a narrow zone, situated near the contact areas. This zone decreases if the rotation velocity increases. Thermal maps are established to globally visualise the roller temperature. They show a localized heating near the contacts and temperature homogeneity in the central zone. 


\section{References}

[1] M. Hamraoui, Thermal behaviour of rollers during the rolling process, Applied Thermal Engineering, 29 (11-12) (2009) 2386-2390

[2] M. Hamraoui, Z Zouaoui, Modelling of heat transfer between two rollers in dry friction, International Journal of Thermal Sciences, 48 (6) (2009) 1243-1246

[3] N. Laraqi, Velocity and relative contact size effect on the thermal constriction resistance in sliding solids, ASME J. Heat Transfer, 119 (1997) 173-177.

[4] T. Osman, A. Boucheffa, Analytical solution for the 3D steady state conduction in a solid subjected to a moving rectangular heat source and surface cooling, Comptes Rendus Mecanique, 337 (2) (2009) 107-111

[5] A. Yevtusherko, O. Ukhanska, Plane contact of thermoelasticity with quasi-steady frictional heating, Int.J. Engineering Science 31 (11) (1993) 1565-1573

[6] A. Baïri, N. Alilat, J.G. Bauzin, N. Laraqi, Three-dimensional stationary thermal behavior of a bearing ball, Int. J. Thermal Sc. 43(6) (2004) 561-568.

[7] N. Alilat, A. Baïri, N. Laraqi, Three-dimensional calculation of temperature in a rotating disk subjected to an eccentric circular heat source and surface cooling, Numerical Heat Transfer 46(2) (2004) 167-180.

[8] H. Yapıcı, M.S. Genç, G. Özışık, Transient temperature and thermal stress distributions in a hollow disk subjected to a moving uniform heat source, Journal of thermal stress 31(2008) 476-493.

[9] N. Laraqi, N. Alilat, J.M. Garcia-de-Maria, A. Baïri, Temperature and division of heat in a pin-on-disc frictional device - Exact analytical solution, Wear, 266 (7-8) (2009) 765-770.

[10] B. Salti, N. Laraqi, 3-D Numerical Modeling of Heat Transfer between Two Sliding Bodies. Temperature and Thermal Contact Resistance', Int. J. Heat Mass Transfer 42 (13) (1999) 2363-2374.

[11] J.P. Bardon, Bases physiques des conditions de contact thermique imparfait entre milieux en glissement relatif, Revue Générale de Thermique Fr. 386 (1994) 86-91.

[12] J.G. Bauzin, N. Laraqi, Simultaneous estimation of frictional heat flux and two thermal contact parameters for sliding solids, Numerical Heat Transfer 45 (4) (2004) 313-328.

[13] A. Baïri, J.M. Garcia-de-Maria, N. Laraqi, Effect of thickness and thermal properties of film on the thermal behavior of moving rough interfaces, European Physical Journal Applied Physics, 26 (1) (2004) pp. 29-34.

[14] B. Gecim, W.O. Winer, Transient Temperature in the Vicinity of an Asperity Contact, ASME Journal of Tribology 107 (1985) pp. 333-342. 


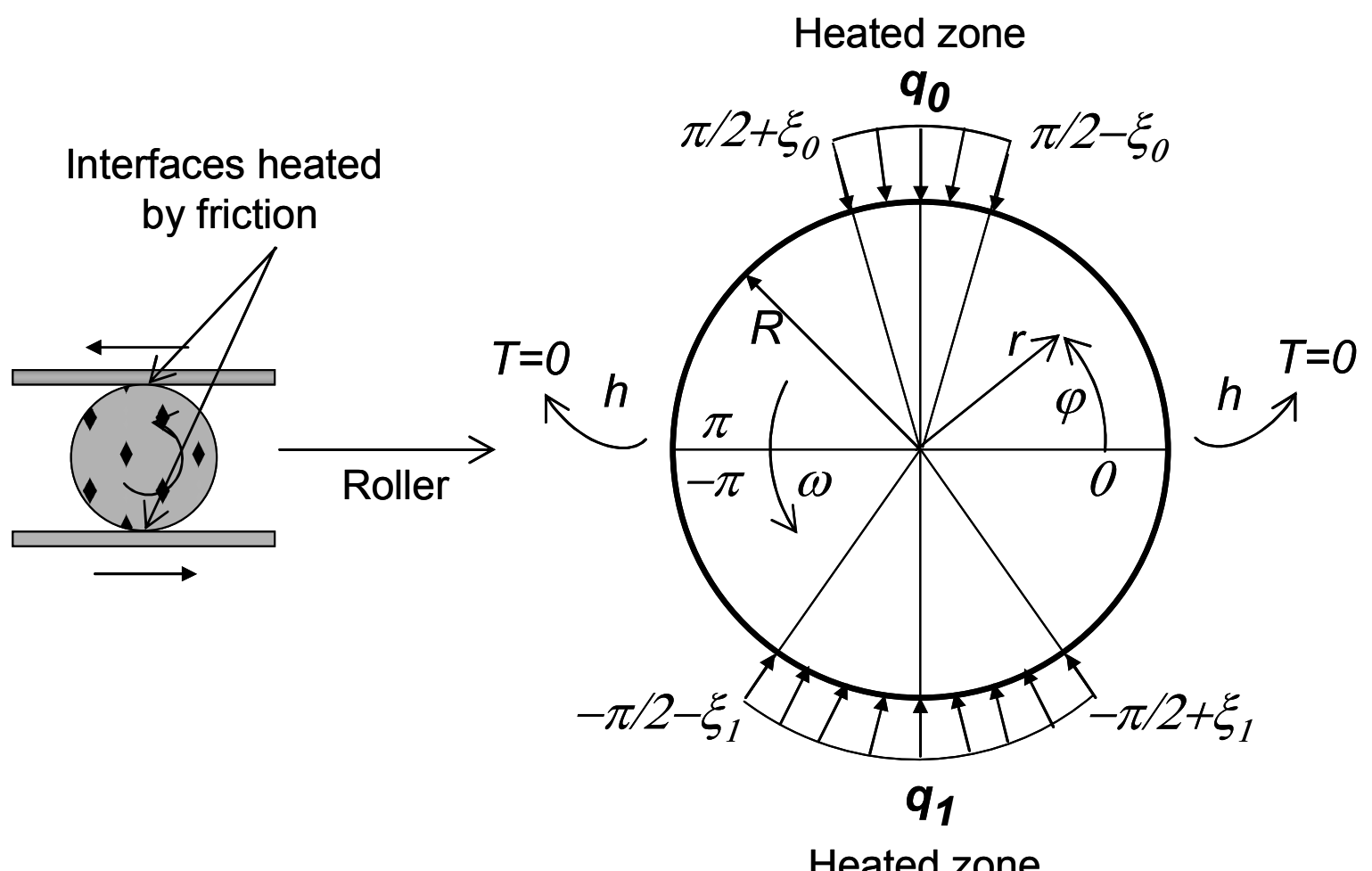

Fig. 1. Studied problem

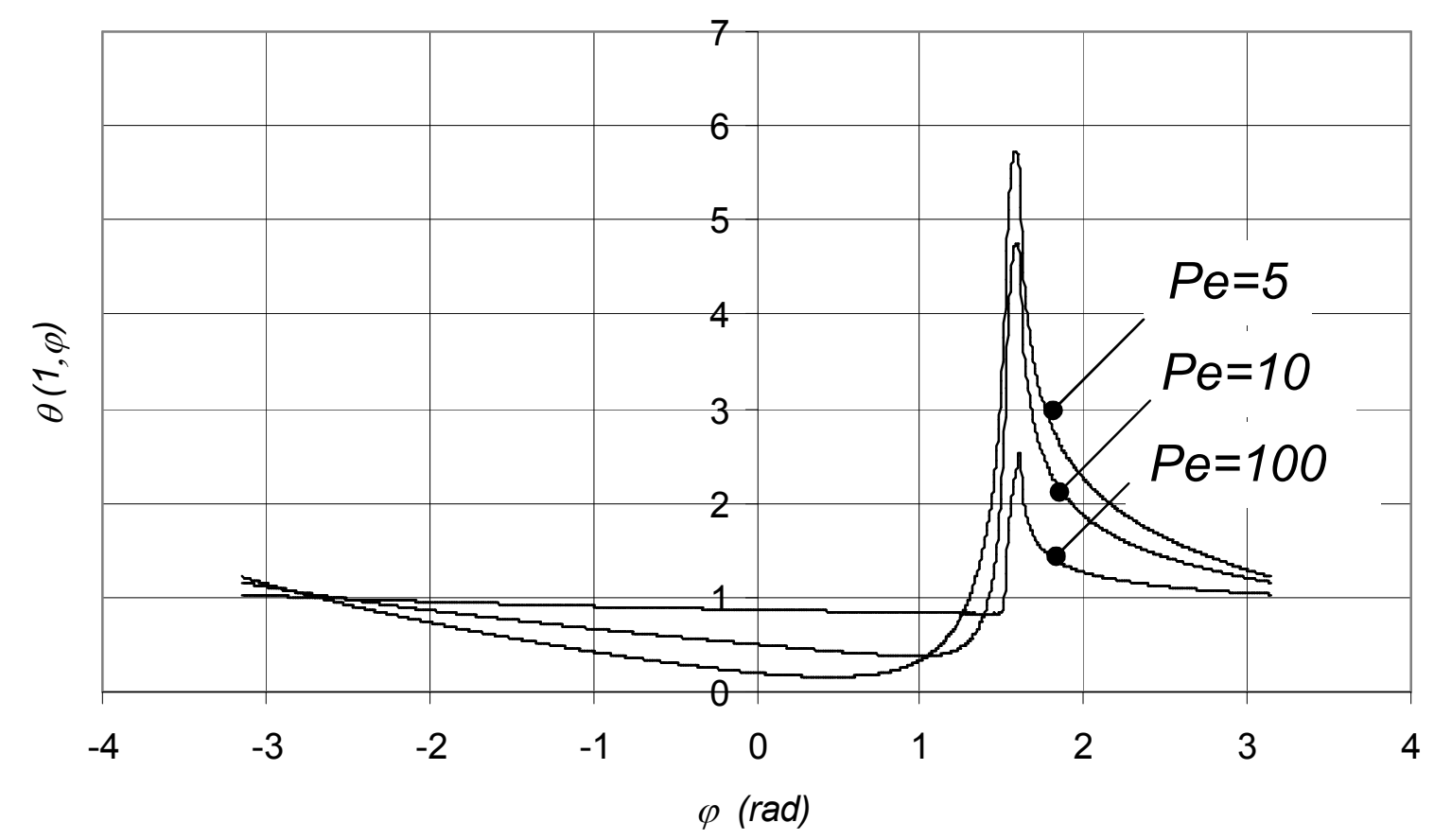

Fig. 2. Dimensionless surface temperature for: $B i=1, q_{1}=0, \xi_{0}=0.05$ at different values of $P e$ (case of a single contact) 

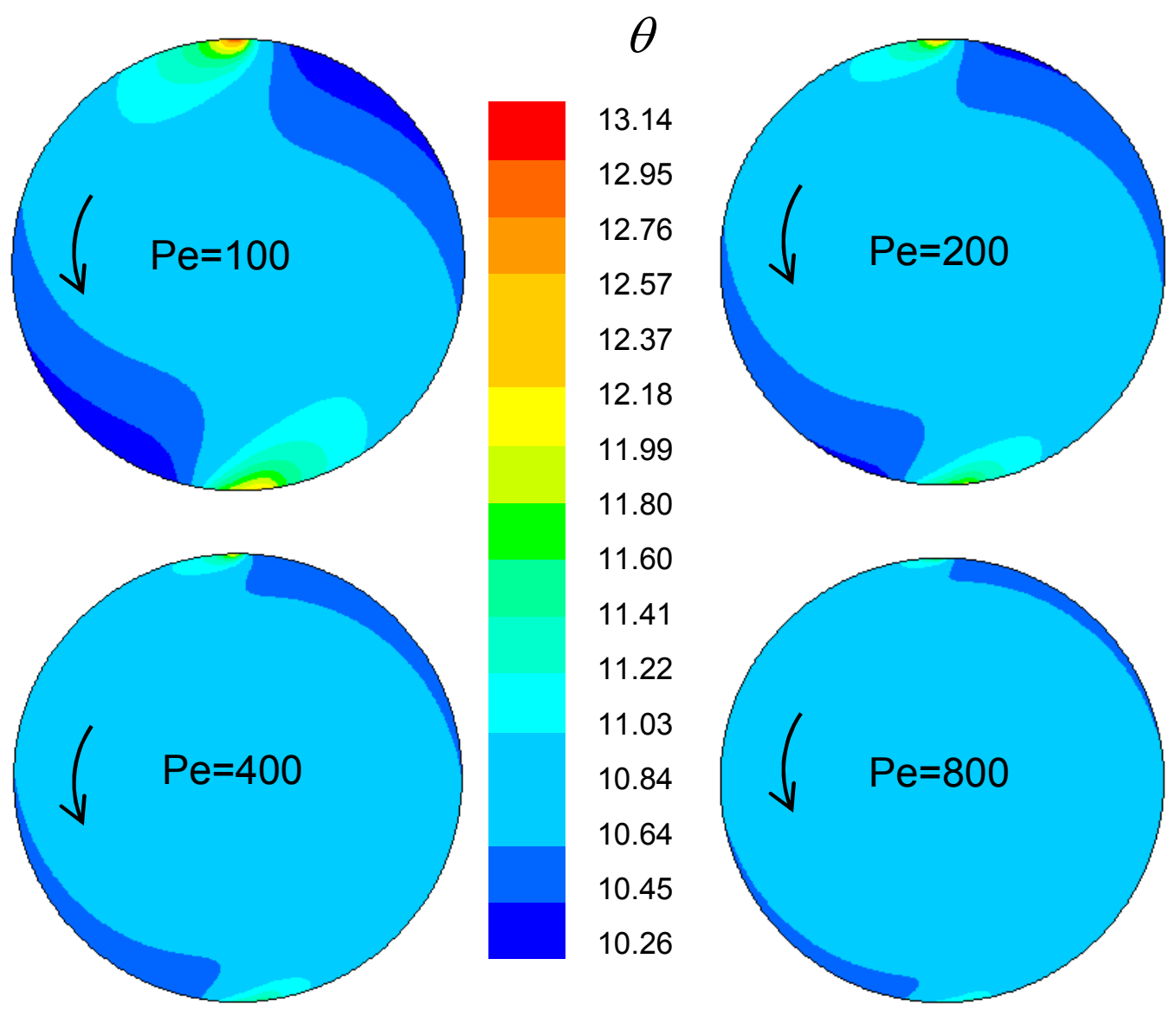

Fig. 3. Thermal map of roller at different velocities (or Peclet number) : $\lambda=20 \mathrm{~W} \cdot \mathrm{m}^{-1} \cdot \mathrm{K}^{-1}$, $\alpha=5.10^{-6} \mathrm{~m}^{2} . \mathrm{s}^{-1}, R=0.01 \mathrm{~m}, \xi_{0}=0.04 \mathrm{rad}, \xi_{1}=0.16 \mathrm{rad}, h=200 \mathrm{~W} . \mathrm{m}^{-2} \cdot \mathrm{K}^{-1}$, $q_{0}=5.10^{5} \mathrm{~W} . \mathrm{m}^{-2}, q_{1}=1.210^{5} \mathrm{~W} \cdot \mathrm{m}^{-2}$. 


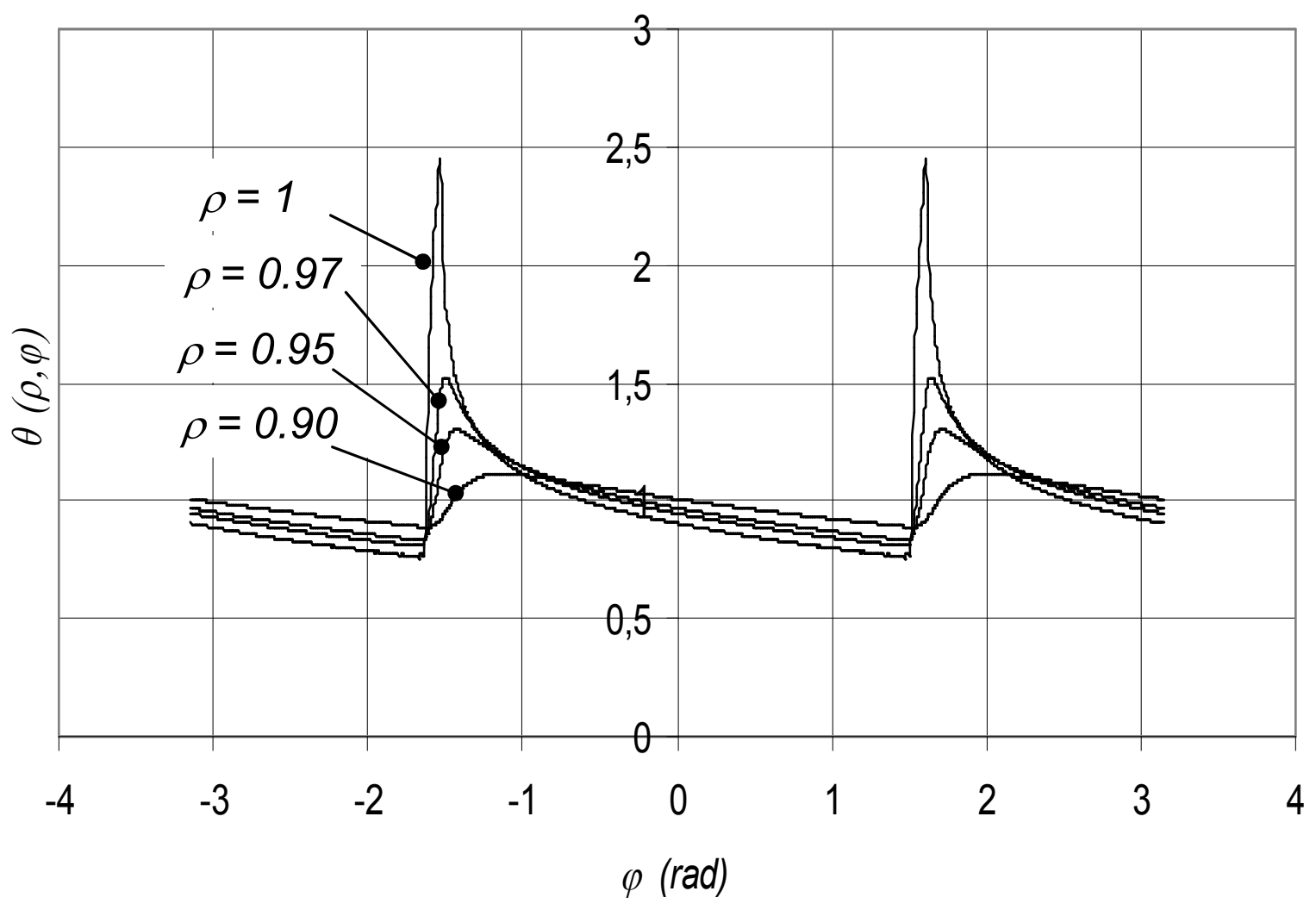

Fig. 4. Dimensionless surface temperature at different radii for: $P e=100, B i=1$, $\xi_{0}=\xi_{1}=0.05 \mathrm{rad}$ 